\title{
Form and Global Consciousness in the Victorian Period
}

\author{
Ayşe Çelikkol* \\ Bilkent University
}

\section{Abstract}

The increased visibility of globalization in the late twentieth and early twenty-first centuries has led scholars in various disciplines from sociology to economics to discuss its impact, scope, and history. Literary criticism is no exception. This essay focuses on Victorian studies, in which the effort to historicize globalization has produced new readings of familiar texts. Recently, scholars of Victorian literature have been unearthing unlikely circuits of cross-cultural interaction, tracing cosmopolitan sentiment, and shedding light on the ideology of the capitalist world system. This essay explores how formal analysis sheds light on the history of globalization.

\section{Introduction}

The increased visibility of globalization in the late twentieth and early twenty-first centuries has led scholars in various disciplines from sociology to economics to discuss its impact, scope, and history. Literary criticism is no exception, and the critical effort to comprehend and assess globalization is by no means limited to the study of contemporary literature. This essay focuses on Victorian studies, in which the effort to historicize globalization has produced new readings of familiar texts. Recently, scholars of Victorian literature have been unearthing unlikely circuits of cross-cultural interaction, tracing cosmopolitan sentiment, and shedding light on the ideology of the capitalist world system.

Special issues or forums published by journals specializing in nineteenth-century British literature reflect this development. Two special issues of Nineteenth-Century Contexts, Nineteenth-Century Worlds: Local/Global (2004) and Global Formations Past and Present (2007), highlight the presence of multinational and transnational networks in the nineteenth century. In the latter volume, Keith Hanley and Greg Kucich describe the nineteenth century as one of the "most significant stages of early globalization" ("Introduction" 74). But to what extent can Victorian studies, a scholarly field traditionally defined by its focus on Britain during the reign of Queen Victoria, address what Hanley and Kucich call "global formations"? A forum on transnationalism in Victorian Studies (2003) addresses this predicament and explores how the field can address cultural, artistic, and political developments that cut across national borders. Sharon Marcus, for example, notes that networks and alliances transcending individual nations were heavily policed by the nation-state and its cultural institutions: "To date those [transnational] frameworks have been most notable in Victorian studies for alerting us both to the porousness of national borders and the violence with which national literatures controlled border crossings" (681-82). The vexed relationship between the national and the transnational is what Victorian studies deftly illuminates.

Recent journal issues devoted to the topic of movement and exchange across Britain's borders in the nineteenth century frequently revisit the role of the nation-state and trace 
its limits. Lauren E. Goodlad and Julia M. Wright, coeditors of Victorian Internationalisms (2007), a special issue of Romanticism and Victorianism on the Net, assert that the effort to historicize globalization must recognize "the nation-state as the product of transnational, translocal, regional, or postcolonial conditions of possibility" ("Introduction and Keywords" 2). For Goodlad and Wright, internationalism is the critical paradigm that achieves this goal. In Victorian Cosmopolitanisms(2010), published by Victorian Literature and Culture, coeditors Tanya Agathocleous and Jason R. Rudy note that the framework of internationalism does not suffice to address "individual activities and stances" that challenged the ideology of the nation-state ("Introduction" 390). Cosmopolitan sentiment the sense of connection to, and sympathy for, peoples living in distant lands - flourished in tandem with imperial arrogance and patriotic fervor, each of these affective states feeding off and renegotiating geopolitics. Behind the preference for the critical concepts of internationalism or cosmopolitanism, then, lie methodological disagreements about the extent to which individual subjects act autonomously in capitalist structures.

Often, studies of global interconnection in the Victorian period raise questions about subjectivity and social structures by addressing form, analyzing style, narration, or plot. Following Ellen Rooney's definition of formalism as "a matter not of barring thematizations but of refusing to reduce reading entirely to the elucidation, essentially the paraphrase, of themes" (29), I suggest that these recent works reflect varying levels and kinds of formalist tendencies. Indeed in literary studies at large there has been a renewed and self-professed fascination with form. In contrast to the New Critical approach, late-twentieth- and twenty-first-century criticism often "insist[s] that form is. .. a feature of every . . . text," non-literary as well as literary (Rooney 33). Partly inspired by the Marxist methodologies of Georg Lukács and Fredric Jameson, many recent formal analyses of language, narration, plot, or genre illuminate relations among politics, culture, and the arts. Susan J. Wolfson has dubbed such criticism "activist formalism" for its commitment to ideological questions (2). As Marjorie Levinson explains, activist formalism "restore[s] to today's reductive reinscription of historical reading its original focus on form" (559). However, alongside activist formalism, a "backlash new formalism" has been burgeoning, which seeks a "return to the sharp demarcation between history and art, discourse and literature" (Levinson 559). The critical works I examine in this essay diametrically oppose this effort to isolate literature from history and politics.

Recently, Caroline Levine has offered a useful survey in Literature Compass that explains how "formalist criticism and historical-political studies of culture join forces" in Victorian Studies ("Formal Pasts" 1244). A broad methodological assessment of the relation between form and politics is beyond the scope of my essay; instead, I seek to answer a more specific question: why should the study of form have the capacity to shed light on the history of globalization? To address this question, I first would like to propose that meditations on form tend to pay attention, and make sense of, the interrelation of heterogeneous elements in a literary work. For example, massive nineteenth-century novels often harmonize multiple subplots. Not that harmony is the only possible aesthetic experience of multiplicity: narrative voices within a novel clash irreconcilably, and heterogeneous discourses that characterize novelistic prose pile up chaotically. Each form embodies an organization of plurality; hence, to create and critique forms is to raise issues that are implicitly political in nature - and, even more specifically, that are at the very core of globalization debates: heterogeneity, unification, and discord. Form offers models for comprehending the stakes of global interconnection and discussing its limits.

Caroline Levine reminds us that "[s]ocial hierarchies and institutions themselves can be understood as forms" (626). As she asserts, the relation between "literary form and social 
formations" is not one of homology. Levine argues that "neither precedes or dominates the other, and they are less likely to reinforce each other than to clash, interrupt, and derail one another" (626). In accord with Levine's formula of complex mediation, the scholarship I examine in this essay asks how literature provides cognitive tools to comprehend, internalize, or critique social forms. As some of these studies suggest, the relation between the literary and the social is dynamic: at any given historical moment, these forms together carve out a matrix of possibility in which each finds its meaning and introduces the possibility of transformation.

In what follows, I examine specific essays and monographs in three subsections ("Parts and Fractured Wholes," "Space and Shape," and "Ideological Clashes") to discuss why reading for form is an effective method for discussing global consciousness in the Victorian period. The first section shows that literary forms facilitated meditations on how, and if, distant parts of the world could be subsumed under an imagined whole. Section two relates literary form to spatial patterns implicit in global relations, and section three explores how literary form draws attention to contradictions within global capitalism. Though each of the critical works I discuss appears in only one of the three subsections, I do not imply that these works belong exclusively to one category. Indeed, most scholarship that appears in this survey explores part-whole relations and spatiality simultaneously, while also remaining alert to ideological contradictions and the historical processes they ignite.

\section{Parts and Fractured Wholes}

The primary denotation of form in the Oxford English Dictionary is "shape, arrangement of parts." Form demands that we think in relational terms and approach any whole as a conglomerate in which constituent elements come into contact. In aesthetic theory, meditations on unity - and its alternatives - figure prominently. For example in Kant's aesthetics beauty has at least the appearance of not being haphazard. In The Critique of Judgment, he posits that in what we perceive as beautiful, we "observe a purposiveness as to form" (65): we feel that it has been created by an agent, for a purpose, following certain rules. For Kant, this "as if' feeling concerns form directly: we sense that the object we deem beautiful is a unified whole. The object's properties, working in unison, create the illusion that they were deliberately made with a purpose in mind. Other philosophers, from Francis Hutcheson to Moses Mendelssohn, have described beauty as the harmony of parts. In literary criticism, the New Critics famously assumed a similar position. Cleanth Brooks singles out harmony as the defining element of aesthetic form: "the primary concern of criticism is with the problem of unity - the kind of whole which the literary work forms or fails to form, and the relation of the various parts to each other in building this whole" (75).

The longing for unity faded after the decline of New Criticism, but critics remained interested in the interrelation of parts. Structuralists approached the whole in terms of parts that define one another. According to this school of criticism, various motifs in a literary work all function together, pointing toward an underlying grammar. Poststructuralists, for whom texts lack boundaries or centers, insisted that unity is illusory and the desire for it is ideological. They located jarring juxtapositions, and paid attention to fractures within seeming wholes. Heir in part to this critical attitude toward unity, and in part to a Marxist approach where totality is a useful framework from which one can recognize reification, critics today - including those who choose to address form, whether that may involve genre, style, or narrative technique - place heterogeneity and sameness 
under critical lenses and explore the processes through which parts confront and coalesce with one another.

Critical approaches to totality and fragmentation are useful for understanding literary form as well as nationhood and globalization. Some recent scholarship in Victorian Studies uses part / whole relations implicit in literary form to offer new insights about the Victorians' sense of connection to distant parts of the world. Regenia Gagnier's Individualism, Decadence, and Globalization: on the Relationship of Part to Whole, 1859-1920 (2010) and Tanya Agathocleous's Urban Realism and the Cosmopolitan Imagination in the Nineteenth Century: Visible City, Invisible World (2011) explore how literary and artistic forms provided new models for embedding local occurrences in global frameworks in the Victorian period. While Gagnier explores the domination of the part over the whole in Decadence, and Agathocleous focuses rather on the presentation of a capacious totality in realism. Together these two studies reveal that literary experiments with part / whole relations opened up questions about the local and the global.

For Gagnier, Decadence helped to cultivate an awareness of geopolitics. Drawing attention to the psychologist Havelock Ellis's definition of Decadence "as when the individuation of parts led to the disintegration of the whole," she notes the recognition of a "Decadent style in literature as an anarchistic style in which everything was sacrificed to the development of the individual parts" (2). As she shows, Decadence prompted the Victorians to ponder the ways in which individual parts dominate the whole, thereby enabling them to recognize and critique early globalization. She writes, "If Decadence indicated when the individuation of parts endangered the survival of the whole, the enormous transfers of wealth from India, Latin America, and China to Europe and North America . . . was seen by perceptive governors and travelers as precisely the Decadence of the West (21). Literary decadence provided a vocabulary for thinking through global power relations.

Realism, too, implies a particular relation between the part and the whole. "If realism involves the search for totality, it relies methodologically on the observation of parts," writes Agathocleous (71). For example, the literary sketch and the panorama comprise a realist approach to the city, interweaving a situated perspective with a hovering one. Victorian novels such as Charles Dickens's Bleak House employ both modes with an overarching plotline that pieces together character sketches. The alternation between situated and hovering perspectives are cosmopolitan in that, through them "London becomes either the world itself or a figure for global modernity," where diverse subjects and spaces comprise a heterogeneous whole microcosmically representing the world (71). Literary form reveals and aestheticizes the processes that go into the imagination of the world as a totality.

If Gagnier and Agathocleous are most directly interested in the ways in which the Victorians related parts to wholes, James Buzard explores the opposite: the isolation of one element out of a heterogeneous set. In Disorienting Fiction: The Autoethnographic work of Nineteenth-Century British Novels(2005) he investigates how one nation's culture appeared to stand apart from the rest - and through that process presented itself as unified. For the Victorians to convince themselves that they had an internally unified culture to call their own, they first would need to isolate a self-enclosed collective unit. Englishness could exist only if there were spatial limits to its reach. For Buzard, the literary form corresponding to this political process is narrative interruption, the moment when an omniscient voice sets limits to its scope, reining in its powers of sympathy. If "the English novelist's way of thinking in global terms was to hold the category of the global at bay," the self-interrupting narrator was the gatekeeper (2). 
Delimiting an allegedly national culture was the condition for imagining its possibility, argues Buzard. Like Buzard, David Kurnick pays attention to the longing for a unified collectivity, but his emphasis is more on the failure of collectivity. Writing on George Eliot's The Spanish Gypsy, Kurnick argues that through the figure of the gypsy, Eliot makes visible the "territory outside national belonging" (492). "[B]anished from the scene of ethnic and national self-presence," the gypsy signals that the nation is not a unified conglomerate, but a vulnerable entity always on the verge of disintegration (495). There's a "shattered collectivity" at the heart of this poem, paralleled by the poem's "shattered form" (496). Indeed, upon its publication the poem was received unfavorably by reviewers whose ideal of art consisted of the harmony of parts. As Kurnick quotes, one reviewer maintained that "Eliot had done "some injury to that sense of artistic completeness [and] broken up rather than connected' the constituent parts of her poem" (495). Noting the clash of genres within the poem and its jarring rhythm, Kurnick shows that the form of the poem embodies the condition of heterogeneity. Through form, Eliot turns people who do not belong to the nation-state into a haunting textual presence.

\section{Space and Shape}

Insofar as form reflects the organization of parts, it overlaps with the distinctly spatial notion of shape. In this section, I shift my focus from parts and wholes to shapes and contours, with the understanding that globalization consists of spatial configurations that change over time. Consider, for example, the dynamics of the capitalist world system: capital diffuses into seemingly isolated corners of the world, and, at the same time, profits derived from new markets return to metropolitan centers for reinvestment in the world of high finance. Highlighting this dual motion, Ian Baucom writes, "globalization must be apprehended not simply as a process of enlargement or expansion, but also, and perhaps more important, as one of contraction and concentration" (160). Baucom employs spatial metaphors to describe global capitalism: "As I imagine it, [global] form resembles a spoked wheel whose expanding rim spins ever more tightly around a glittering metropolitan hub" (160). To think globally is to think simultaneously about multiple points in space, to connect and differentiate them, and that is precisely why experiments with literary form helped the Victorians to reflect on, and to imagine alternatives to, dominant global formations.

In the Powers of Distance: Cosmopolitanism and the Cultivation of Detachment (2001), Amanda Anderson shows that the central paradigm of Victorian cosmopolitanism was spatial: distance. To be a citizen of the world was to abide by an ideal of detachment, from one's own culture, location, or identity. If The Powers of Distance returns again and again to questions of literary form, that may be because the Victorians employed a markedly spatial paradigm to reject narrow-minded nationalism. The resonance of cosmopolitanism with literary form becomes visible, for example, in Oscar Wilde's "most pervasive formal device," the epigram. Anderson writes, "Wilde's concern with the ethics of detachment is played out ... extensively and tellingly through his literary use of the epigram" (151). Like the cosmopolitan ideal of detachment, the epigram involves an act of distancing and stepping beyond. As Anderson shows, the epigram, which occurs so frequently in Wilde's work, "seems always to pull away from the text, and from the context of action, announcing itself as quotable, transferable, and indifferent" (150). The epigram stretches the space it inhabits and produces a gap within the literary text, cultivating the kind of detachment on which Victorian cosmopolitanism depended. 
My own work similarly relates spatial dynamics of nineteenth-century global formations to literary form. In Romances of Free Trade: British Literature, Laissez-Faire, and the Global Nineteenth Century (2011), I argue that in nineteenth-century British literature, formal elements residual from older romances - episodic plot, solitary characters, abstract space - are used to represent a radically new historical formation, the global free market economy. In the public imagination, the global market economy heralded a decentered world in which nation-states lost their hold on individual subjects. The romance genre commented on the emergent economic system by featuring centrifugal motion: adventures begin when a hero leaves centralized order behind and wanders off into uncharted territory. For example, the episodic plot structure of Captain Marryat's seafaring adventures replicate the disorderly, uncontrollable motion that his contemporaries associated with free trade, an economic practice that was in practice heavily controlled by the state (15).

The range of topics covered by Victorianist scholarship on global consciousness signals the diversity of Victorian thinking about politics and society. Exploring cosmopolitanism and its failures alongside nationhood and its cracks, many of the critical works that I have examined complement rather than counter one another. Yet while remaining complementary, they also point toward the absence of a fully dialectical approach. Such an approach would highlight that distinct cultural developments were taking place on the same historical plane, and that heterogeneous elements of the global nineteenth century did not just coexist but made each other possible. For example, we may see the seemingly oppositional categories of nationalism and cosmopolitanism as shaped by common ideologies of difference or identity. ${ }^{1}$ It is necessary to uncover the heterogeneity of Victorian thought about global relations while at the same time acknowledging the systemic interplay of elements within a unified capitalist system.

\section{Ideological Clashes}

In individual forms such as a sentence, a stanza, or what Henry James called a "loose baggy monster," the novel, oppositional ideas or competing perspectives are yoked together, but not reconciled (x). Holding together irreconcilable difference, individual forms often manifest contradictory aspects of an ideological system or manage them. Reading for form tunes critics in to historical processes that appear oppositional, yet coexist. For example, Garrett Stewart discusses the codependence of material and metaphysical concerns under capitalism, and Lauren Goodlad traces the rivalry between older forms of property ownership and cosmopolitan entrepreneurship.

Garrett Stewart's "The Foreign Offices of British Fiction," which offers a formalist approach to Charles Dickens's Dombey and Son while at the same time contributing to postcolonial literary study, focuses on syllepsis. Consisting of a "skewed parallelism" in grammar - as in the statement "we pass out into adventure and sunshine" in E. M. Forster's Howard's End - this rhetorical figure embodies a doubleness, where the splitting creates a moment of "divided cognition" (Stewart 186, 190, 183). At the sentence level, syllepsis occurs with remarkable frequency in Dombey and Son, where it embodies in miniature form "the novel's explicit imperial thematic of divided vision": metaphysical matters such as death in all its sublimity stand juxtaposed with material concerns, but neither characters nor the narrative voice can relate one to the other (184). In Dickens's prose, references to Mr Dombey's lucrative oceanic trade and the " "unknown sea" that " "rolls round the world", stand in jarring parallel (197). The forking between the 
terrestrial and the transcendental, Stewart argues, reveals syllepsis to be the figure of a "culturally sanctioned thing: the attempted resolution of incommensurables" (205).

Like Stewart, Goodlad explores a divided vision that reveals contradictions that it cannot reconcile. As in Dickens, so in Trollope: the codependence of seemingly irreconcilable values characterizes global capitalism. In "Trollopian 'Foreign Policy': Rootedness and Cosmopolitanism in the Mid-Victorian Global Imaginary," Goodlad suggests that, while Trollope's Barsetshire novels idealize heirloom "property that accumulates particular ethical and cultural worth in excess of abstract economic value," his travel writings present another kind of property, tended by "rootless cosmopolitans" who turn it into abstract value $(443,447)$. Together, these two genres present a bifurcated structure. Goodlad argues that the tension between these two modes shapes the plotlines of what she calls Trollope's "global capitalist novels," where "Hobbesian combatants struggle to wrest money and power away from the all-but-substanceless flow of capital and commodities" (448). In these novels, England's ruling class is not what it used to be, and its members do not so much embrace heirloom values as employ the discourse of rootless cosmopolitans. Goodlad's argument exemplifies the possibilities for dialectical thinking implicit in formal analysis.

Featuring juxtapositions where the residual meets the emergent, or where rivaling ideologies clash with one another, literary form can draw our attention to historical contradictions and transformations. At the same time, as Susan Wolfson and Ellen Rooney point out, reading for form keys the reader in to the specific cultural work a text performs, which cannot be equated with the work of any ideology or theory that precedes it. Resisting universal or abstract formulations, the critical works that I have briefly examined treat fantasies and materialities of the global as locally embedded, and in doing so assert the limits of globalizing forces and the multiplicity of ways in which they manifest themselves.

\footnotetext{
Notes

* Correspondence: Ayşe Çelikkol, Bilkent University, Bilkent Uni, ELIT, Ankara 06800, Turkey. Email: celikkol@bilkent.edu.tr

1 In positing that ideologies of similarity and difference operate through the global and the national, I am following Fredrick Jameson's formulation in "Globalization as a Philosophical Issue." Observing that "multiplicity is celebrated against an oppressive unity" in Latin America and that "a positive unity is defended against an oppressive multiplicity" in North America, Jameson revisits Hegelian categories of Identity and Difference, which are "one and the same as each other" $(451,454)$.
}

\section{Works Cited}

Agathocleous, Tanya. Urban Realism and the Cosmopolitan Imagination in the Nineteenth Century: Visible City, Invisible World. New York: Cambridge University Press, 2011.

Agathocleous, Tanya and Jason R. Rudy. 'Introduction to Victorian Cosmopolitanisms.' Eds. Tanya, Agathocleous and Jason R. Rudy. Special issue of Victorian Literature and Culture 38.2 (2010): 389-97.

Anderson, Amanda. The Powers of Distance: Cosmopolitanism and the Cultivation of Detachment. Princeton: Princeton University Press, 2011.

Baucom, Ian. 'Globalit, Inc.; or, the Cultural Logic of Global Literary Studies.' Globalizing Literary Studies. Special Issue of PMLA: Publications of the Modern Language Association of America 116.1 (2001): 158-72.

Brooks, Cleanth. 'My Credo.' Kenyon Review 13 (1951): 75.

Buzard, James. Disorienting Fiction: The Autoethnographic Work of Nineteenth-Century British Novels. Princeton: Princeton University Press, 2005.

Celikkol, Ayșe. Romances of Free Trade: British Literature, Laissez-Faire, and the Global Nineteenth Century. New York: Oxford University Press, 2011. 
Gagnier, Regenia. Individualism, Decadence, and Globalization: On the Relationship of Part to Whole, 1859-1920. New York: Palgrave, 2010.

Goodlad, Lauren E. 'Cosmopolitanism's Actually Existing Beyond; Toward a Victorian Geopolitical Aesthetic.' Victorian Cosmopolitanisms. Eds. Tanya, Agathocleous and Jason R. Rudy. Special issue of Victorian Literature and Culture 38.2 (2010): 399-411.

—. 'Trollopian 'Foreign Policy': Rootedness and Cosmopolitanism in the Mid-Victorian Global Imaginary.' PMLA: Publications of the Modern Language Association of America 124.2 (2009): 437-54.

Goodlad, Lauren E., and Julia M. Wright, eds. 'Introduction and Keywords.' Victorian Internationalisms. Special issue of Romanticism and Victorianism on the Net 48 (2007): para.1-26.

Jameson, Fredrick. 'Globalization as a Philosophical Issue.' Valences of the Dialectic. New York: Verso, 2009.

James, Henry. Preface. The Tragic Muse. 2 vols. New York: Scribner, 1908.

Kant, Immanuel. Critique of Judgment. Trans. Werner S. Pluhar. Indianapolis: Hackett, 1987.

Kucich, Greg and Keith Hanley, eds. Nineteenth-Century Worlds: Local/Global. Special issue of NineteenthCentury Contexts 26.4 (2004).

- and - eds. 'Introduction: Global Formations and Recalcitrances.' Global Formations Past and Present. Eds. Greg Kucich and Keith Hanley. Special issue of Nineteenth-Century Contexts 29.2-3 (2007): 73-88.

Kurnick, David. 'Unspeakable George Eliot.' Victorian Literature and Culture 38 (2010): 489-509.

Levine, Caroline. 'Formal Pasts and Formal Possibilities in Victorian Studies.' Literature Compass 4.4 (2007): $1441-56$.

—. 'Strategic Formalism: Toward a New Method in Cultural Studies.' Victorian Studies 48 (2006): 625-55.

Levinson, Marjorie. 'What is New Formalism?' PMLA: Publications of the Modern Language Association of America 122.1 (2007): 558-69.

Marcus, Sharon. 'Same Difference? Transnationalism, Comparative Literature, and Victorian Studies.' Victorian Studies 45.4 (2003): 677-86.

Rooney, Ellen. 'Form and Contentment.' MLQ: Modern Language Quarterly 61.1 (2000): 17-40.

Stewart, Garrett. 'The Foreign Offices of British Fiction.' Modern Language Quarterly 61.1 (2000): 181-206.

Wolfson, Susan J. 'Introduction: Reading for Form.' MLQ: Modern Language Quarterly 61.1 (2000): 1-16. 